\title{
Formação dos agentes comunitários de saúde no município de Altamira (PA), Brasil
}

\author{
Training of community health agents in the city of Altamira (Pará), Brazil \\ Lagerson Mauad Freitas ${ }^{1}$, Maria Wanderleya de Lavor Coriolano-Marinus², Luciane Soares de Lima², Lidia Ruiz-Moreno³ \\ 'Universidade do Estado do Pará (UEPA) - Belém (PA), Brasil. \\ ${ }^{2}$ Departamento de Enfermagem, Universidade Federal de Pernambuco (UFPE) - Recife (PE), Brasil \\ ${ }^{3}$ Centro de Desenvolvimento do Ensino Superior em Saúde (CEDESS), Universidade Federal de São Paulo (UNIFESP) - São Paulo (SP), Brasil.
}

DOI: http://dx.doi.org/10.7322/abcshs.v40i3.791

\section{RESUMO}

Introdução: A expansão da Estratégia Saúde da Família (ESF) coloca em destaque o Agente Comunitário de Saúde (ACS) na condição de importante ator social na viabilização do Sistema Único de Saúde (SUS). Objetivo: Caracterizar o perfil socioeconômico e demográfico, processo de formação e o papel educativo junto à comunidade do ACS no município de Altamira (PA). Métodos: O estudo, de caráter descritivo-exploratório, utilizou para a coleta de dados questionário semiestruturado aplicado a 63 ACS. Os dados foram tabulados no Programa Excel e expressos em frequências absoluta e relativa. A análise temática foi utilizada para as questões relacionadas à formação do ACS. Resultados: O perfil socioeconômico dos agentes evidencia aspectos similares aos da comunidade atendida. A maioria dos participantes considera que recebeu formação para atender as atribuições legais. As demandas de formação dos ACS referem-se a conhecimentos específicos sobre álcool e drogas e vigilância em saúde, procedimentos técnicos de saúde, comunicação, relacionamento interpessoal, ética e identidade profissional. As ações educativas desenvolvidas pelos ACS na comunidade compreendem palestras e visitas domiciliares Conclusão: Observa-se a importância da normatização do processo de formação do ACS de forma a oferecer subsídios para o desenvolvimento de ações educativas dialógicas e contribuir com a construção da identidade desse profissional que ocupa espaço estratégico nas políticas brasileiras de atenção básica.

Palavras-chave: educação; saúde; agentes comunitários de saúde; conhecimentos, atitudes e prática em saúde.

\begin{abstract}
Introduction: The development of the Family Health Strategy puts emphasis on the Community Health Agents (CHA) as an important social actor in the viability of the Unified Health System. Objective: To characterize the socioeconomic and demographic profile, the training process and educational role at the $\mathrm{CHA}$ in city of Altamira (PA), Brazil. Methods: This descriptive and exploratory study used to collect data a semi-structured questionnaire applied to $63 \mathrm{CHA}$. Data were tabulated in Excel program and expressed as absolute and relative frequencies. Thematic analysis was used for questions related to the formation of the CHA. Results: The socioeconomic profile of agents showed similar aspects to those of the community assisted. Most of the participants consider that received the training to attend the legal attributions. The demands of training of $\mathrm{CHA}$ refers to specific knowledge about alcohol and drugs and health surveillance, technical procedures in health, communication, interpersonal relationship, ethics and professional identity. Educational activities conducted by $\mathrm{CHA}$ in the community involved lectures and home visits. Conclusion: It was observed the importance of normalization of the training process of the $\mathrm{CHA}$ to offer subsidies for the development of dialogical educational activities and contribute in the construction of the identity of this professional occupying a strategic place in Brazilian primary care policies.
\end{abstract}

Keywords: education; health; community health workers; health knowledge, attitudes, practice. 


\section{INTRODUÇÃO}

O Programa de Agentes Comunitários de Saúde (PACS), no contexto da atenção primária, teve início em 1987 no Ceará com ações voltadas para o grupo materno-infantil, criando oportunidades de trabalho para mulheres no período de seca e reduzindo os índices de mortalidade infantil. Em virtude do sucesso do programa, em 1991, foi ampliado para todo o território nacional ${ }^{1}$.

O Agente Comunitário de Saúde (ACS) representa o elo entre comunidade e o serviço de saúde, tendo importância para a efetivação do atual modelo de assistência. Segundo o Ministério da Saúde, a política nacional de saúde se embasa na Estratégia do Agente Comunitário de Saúde e na Estratégia Saúde da Família (ESF), valorizando a atenção primária para o fortalecimento e a integralidade das ações na comunidade ${ }^{2,3}$.

Após a implantação do Programa de Saúde da Família (PSF), o papel do ACS foi ampliado, saiu do foco materno-infantil para abranger o cuidado à família e comunidade, o que exige novas competências no campo político, social e no seu processo de formação. É consenso que o ACS seja alguém inserido na comunidade, que se identifica, na cultura, linguagem e costumes com a população para o exercício de suas funções.

A profissão de Agente Comunitário de Saúde caracteriza-se pelo exercício de atividade de prevenção de doenças e promoção da saúde, mediante ações domiciliares comunitárias, individuais ou coletivas, desenvolvidas pelo SUS e sob supervisão do gestor local ${ }^{4}$.

Assim, o ACS transita uma construção histórica de sua identidade profissional. O "profissional" leigo foi escolhido por seu potencial transformador, com possibilidade para a formação de uma consciência crítica nas comunidades, embasado no aporte teórico de Paulo Freire, relacionado à educação popular ${ }^{5}$. Desse modo, é necessário que o ACS tenha um grau de escolaridade mais elevado, para dar conta dessas novas demandas ${ }^{1}$.

A formação do ACS precisa envolver não apenas conhecimentos básicos sobre o processo de saúde-doença, mas estratégias educativas individuais e coletivas que valorizem a troca de saberes, experiências e autonomia dos usuários. As práticas educativas dialógicas e de trabalho em grupo podem facilitar a produção coletiva de conhecimento e a reflexão sobre a realidade, sendo este um importante aspecto para o desenvolvimento do processo reflexivo que sinalize para estratégias de enfrentamento dos desafios que fazem parte das situações de saúde.

Com base na importância do trabalho do ACS na conjuntura do Sistema Único de Saúde (SUS) em regiões com elevadas demandas, este artigo tem o objetivo de caracterizar o perfil socioeconômico e demográfico dos ACS da cidade de Altamira (PA), e o processo de formação e entendimento do seu papel educativo junto à comunidade.

\section{MÉTODOS}

A presente pesquisa define-se descritivo-exploratória, com abordagem quanti-qualitativa ${ }^{6-8}$.
O contexto da pesquisa foi a cidade de Altamira (PA), município de maior extensão territorial do mundo, sendo referência para toda região Transamazônica e área do Xingu. Integra essa regional de saúde o $10^{\circ}$ Centro Regional de Saúde/Secretaria Estadual de Saúde do Pará (CRS/SESPA), além dos nove municípios que a conformam.

A população da cidade consta de aproximadamente 105.030 habitantes ${ }^{9}$, com maior concentração na zona urbana. A construção da Usina Hidrelétrica de Belo Monte, terceira maior hidrelétrica do mundo, iniciada em 2011, cria complexos impactos ambientais, culturais, econômicos e sociais.

Desde o início, a construção da usina gerou milhares de empregos com a consequente imigração de trabalhadores a uma região com baixos índices de desenvolvimento humano. A falta de planejamento tem como consequência a desorganização social nas aldeias da região, mas é em Altamira, cidade próxima mais importante da Volta Grande do Xingu, onde os impactos são mais evidentes. $\mathrm{O}$ aumento da violência, acidentes de trânsito, poluição e destruição da natureza criam desafios para os gestores locais, especialmente na área da saúde.

A Secretaria Municipal de Saúde do município de Altamira possui, na zona urbana, 12 equipes na ESF, com 81 ACS. Na zona rural, existe apenas a estratégia de Agente Comunitário de Saúde onde atuam 48 ACS, totalizando 129 ACS.

O universo de 81 ACS da zona urbana do município de Altamira foi convidado a participar da presente pesquisa, dos quais 63 (78\%) aceitaram. Zelando pelo anonimato dos participantes, aos mesmos foram atribuídos números, em ordem crescente (ACS1 a ACS63). A pesquisa foi aprovada pelo Comitê de Ética em Pesquisa da Universidade Federal de São Paulo (Processo: 132.074).

A coleta de dados ocorreu no período de dezembro de 2012 a janeiro de 2013 e consistiu na aplicação de questionário semiestruturado. Os dados foram tabulados no Programa Excel e expressos em frequências absoluta e relativa. A análise compreendeu tratamento estatístico descritivo dos dados relativos ao perfil socioeconômico e demográfico e atribuições legais. A análise temática foi utilizada para as questões relacionadas ao processo de formação do ACS.

\section{RESULTADOS E DISCUSSÃO}

Sobre o perfil socioeconômico dos ACS foram investigados aspectos sobre a idade, naturalidade, sexo, estado civil, cor da pele autodeclarada, rendimento mensal, tempo de trabalho como ACS, escolaridade (Tabela 1).

A maioria dos ACS, no momento da coleta de dados, tinha entre 43 e 47 anos e entre 33 a 37 anos (24\% respectivamente), seguida de 38 a 42 anos (16\%). A metade dos ACS (50,8\%) é originária da cidade de Altamira, 12\% vêm do Estado do Maranhão, e 46\% são oriundos de outros estados brasileiros como: Amapá, Tocantins, Ceará, Pernambuco, Rio Grande do Norte, Espírito Santo, Minas Gerais e Rio Grande do Sul provavelmente em busca de melhores condições de vida ${ }^{10}$. 
Quando criado o Programa de Saúde da Família, hoje denominado Estratégia de Saúde da Família, foram convidados para ser ACS os presidentes de associação de moradores e líderes comunitários, pois já desenvolviam atividades em prol da comunidade e o exercício dessa função representava uma oportunidade de reingresso no mundo de trabalho ${ }^{11}$.

A maioria dos ACS pesquisados neste estudo são de sexo feminino, $56(88,9 \%)$ e apenas $7(11,1 \%)$ do masculino. Diversos autores associam o trabalho do ACS ao trabalho feminino, já que

Tabela 1: Perfil socioeconômico, demográfico e escolaridade dos Agentes Comunitários de Saúde - Altamira (PA), 2013

\begin{tabular}{|c|c|c|}
\hline Variável & $n$ & $\%$ \\
\hline \multicolumn{3}{|l|}{ Sexo } \\
\hline Masculino & 7 & 11,1 \\
\hline Feminino & 56 & 88,9 \\
\hline \multicolumn{3}{|l|}{ Idade (anos) } \\
\hline 28 a 32 & 10 & 15,9 \\
\hline 33 a 37 & 15 & 23,9 \\
\hline 38 a 42 & 10 & 15,9 \\
\hline 43 a 47 & 15 & 23,9 \\
\hline 48 a 52 & 8 & 12,7 \\
\hline 53 a 58 & 5 & 7,9 \\
\hline \multicolumn{3}{|l|}{ Estado civil } \\
\hline Casado & 27 & 43 \\
\hline Solteiro & 22 & 35 \\
\hline Viúvo & 1 & 1,5 \\
\hline Outros & 13 & 20,6 \\
\hline \multicolumn{3}{|l|}{ Cor da pele autodeclarada } \\
\hline Parda & 42 & 66,7 \\
\hline Branca & 11 & 17,5 \\
\hline Preta & 7 & 11,1 \\
\hline Indígena & 2 & 3,2 \\
\hline Amarela & 1 & 1,6 \\
\hline \multicolumn{3}{|l|}{ Rendimento mensal } \\
\hline 0 a 1 salário mínimo & 57 & 90,5 \\
\hline 1 a 2 salários mínimos & 1 & 1,6 \\
\hline 2 a 3 salários mínimos & 5 & 7,9 \\
\hline \multicolumn{3}{|l|}{ Início das atividades como ACS } \\
\hline Antes de 1998 & 8 & 12,7 \\
\hline 1998 a 2001 & 8 & 12,7 \\
\hline 2002 a 2004 & 9 & 14,3 \\
\hline 2005 a 2007 & 38 & 60,3 \\
\hline \multicolumn{3}{|l|}{ Escolaridade } \\
\hline Ensino fundamental incompleto & 3 & 4,8 \\
\hline Ensino fundamental completo & 4 & 6,3 \\
\hline Ensino médio incompleto & 6 & 9,5 \\
\hline Ensino médio completo & 41 & 65,1 \\
\hline Ensino superior incompleto & 6 & 9,5 \\
\hline Ensino superior completo & 3 & 4,8 \\
\hline \multicolumn{3}{|l|}{ Outra formação } \\
\hline Técnico em enfermagem & 13 & 65,0 \\
\hline Técnico em ACS & 1 & 5,0 \\
\hline Técnico em segurança do trabalho & 2 & 10,0 \\
\hline Técnico administrativo & 2 & 10,0 \\
\hline Teologia & 1 & 5,0 \\
\hline Pedagogia & 1 & 5,0 \\
\hline
\end{tabular}

ACS: Agente Comunitário de Saúde. a mulher possui uma inclinação reconhecida para o cuidado em saúde. Relacionam o elevado número de mulheres na profissão de ACS com achados históricos e relatam em sua pesquisa o fato da mulher ser vista, já desde a idade média, como cuidadora ${ }^{11,12}$.

O questionamento sobre o estado civil dos ACS mostrou que 27 (43\%) são casados, $22(35 \%)$ solteiros, 1 (1,5\%) viúvo e $13(20,6 \%)$ têm outros tipos de relacionamentos. O estado civil ou vínculo conjugal desses profissionais também pode ser um indicador de permanência na microárea onde moram e trabalham.

A distribuição dos ACS segundo cor da pele autodeclarada evidenciou predominância da cor parda, com 42 (66,7\%); em seguida, branca, com 11 (17,5\%), preta, 7 (11,1\%), 2 (3,1\%) indígenas e $1(1,5 \%)$ amarelo, o que mostra semelhanças com o conjunto da população da Região Norte, identificando-o como integrante representativo da comunidade que assiste já que a composição populacional da Região Norte ${ }^{9}$ apresenta proporções semelhantes.

A portaria $n^{\circ} 2.488$ do Ministério da Saúde especifica que esse profissional receba um salário mínimo pela sua função. A renda mensal de 57 ACS pesquisados corresponde a um salário mínimo, um tem rendimento de dois salários e cinco recebem três salários mínimos. Os seis ACS que recebem mais de um salário, complementam a renda trabalhando como garçons, atendentes e outros, fora do seu horário de serviço.

No município estudado a maioria dos ACS iniciou suas atividades no período de 2005 a 2007, com 38 ACS, sendo que 25 ingressaram em anos anteriores. Observa-se que ainda há ACS atuando desde a implantação do programa na Secretaria de Saúde, na década de 1990, e que hoje estão locados na Estratégia Saúde da Família (ESF).

A partir de 2006, foi conquistada a contratação formal e direta pelo Estado, mediante seleção pública para os $\mathrm{ACS}^{13}$. Entretanto, esses direitos conquistados, fruto da luta e mobilização coletiva dos ACS, não eram assegurados, mantendo-se a precarização dos vínculos de trabalho e da formação profissional. Foi com a Lei 11.350, de outubro de 2006 que se garante seu vínculo laboral efetivo.

Sua integração na equipe de saúde é justificada pela suposta dificuldade dos profissionais de saúde de se relacionarem adequadamente com a população. Os ACS participantes da pesquisa caracterizam-se, essencialmente, por apresentar um perfil socioeconômico semelhante ao conjunto da população atendida o que pode ser um aspecto facilitador para o seu papel de mediador.

Esses atores ocupam posição privilegiada na dinâmica de implantação e consolidação de um novo modelo assistencial, centrado na promoção em saúde. Sua percepção em relação à realidade de cada comunidade é ponto fundamental para o processo educativo e participativo da população ${ }^{14}$.

Em relação à escolaridade dos ACS que compõem a ESF, entre os 63 pesquisados, 3 têm ensino superior completo, 6 , ensino superior incompleto, 41 , ensino médio, 6 , ensino médio incompleto, 4, ensino fundamental completo e 3, fundamental incompleto. Observa-se que o nível de escolaridade está concentrado no ensino médio. 
A escolarização ainda se apresenta como um aspecto que vem mudando com o passar dos anos de existência desse trabalhador do SUS. Pesquisadores relatam em sua pesquisa que, na ESF, 9,6\% dos ACS possuíam apenas o ensino fundamental e atualmente este índice é de apenas 2,7\%; o nível de instrução predominante é o nível médio, em concordância com os dados encontrados na presente pesquisa ${ }^{12}$. Quanto maior o grau de escolaridade mais condições terá o ACS de incorporar novos conhecimentos e orientar as famílias sob sua responsabilidade ${ }^{15}$.

Apesar de o ACS desenvolver um trabalho complexo, caracterizado principalmente pela dimensão educativa, em geral, sua formação profissional tem sido marcada pela precariedade e descontinuidade, considerando que, para essa função, desde a criação do PACS, o Ministério da Saúde estabelecia como critérios de escolaridade apenas as habilidades de ler e escrever.

Quando os ACS, participantes da presente pesquisa, foram interrogados se realizaram outra formação, apenas 20 responderam afirmativamente. Observa-se predominância do curso Técnico de Enfermagem, seguido de Técnico em ACS; Técnico em Segurança no Trabalho, Técnico em Agente Administrativo e cursos de nível superior de Teologia e Pedagogia.

A normatização do Ministério da Saúde, portaria n 2.488, destaca que o ACS, antes de ir para comunidade, deverá participar de um curso de Formação Inicial, oferecido pela respectiva Secretaria Municipal de Saúde. Entretanto, os dados deste estudo mostraram que apenas 48 (76\%) dos ACS realizaram esse curso, sendo que 15 (24\%) não o frequentaram por falta de oferta da própria secretaria. $\mathrm{Na}$ Tabela 2, se apresentam a carga horária e a avaliação dos ACS sobre o preparo para desenvolver ações educativas e as atribuições previstas na legislação durante o curso de formação.

Tabela 2: Características do processo de formação no curso inicial de Agentes Comunitários de Saúde - Altamira (PA), 2013

\begin{tabular}{|c|c|c|}
\hline Variável & $\mathbf{n}$ & $\%$ \\
\hline \multicolumn{3}{|c|}{ Realização de Curso inicial } \\
\hline Sim & 48 & 76,2 \\
\hline Não & 15 & 23,8 \\
\hline \multicolumn{3}{|c|}{ Carga horária do Curso inicial } \\
\hline $40 \mathrm{~h}$ & 1 & 2,1 \\
\hline $60 \mathrm{~h}$ & 27 & 56,3 \\
\hline $100 \mathrm{~h}$ & 6 & 12,5 \\
\hline $120 \mathrm{~h}$ & 14 & 29,2 \\
\hline \multicolumn{3}{|l|}{ Avaliação do curso } \\
\hline \multicolumn{3}{|c|}{ Preparou para as atribuições legais como ACS } \\
\hline Sim & 52 & 82,5 \\
\hline Não & 8 & 12,7 \\
\hline Parcialmente & 3 & 4,8 \\
\hline \multicolumn{3}{|l|}{ Avaliação do curso } \\
\hline \multicolumn{3}{|c|}{ Preparou para ações educativas } \\
\hline $\operatorname{Sim}$ & 53 & 84,1 \\
\hline Não & 8 & 12,7 \\
\hline Parcialmente & 2 & 3,2 \\
\hline
\end{tabular}

ACS: Agente Comunitário de Saúde.
Ao longo das duas décadas que se seguiram à institucionalização do PACS, a formação e a valorização dos vínculos têm sido os principais objetivos da luta empreendida pela Confederação Nacional dos Agentes Comunitários de Saúde (CONACS). No âmbito legal, vários ganhos foram obtidos, tais como a criação da profissão, no ano 2002, o aumento da escolaridade e a qualificação em nível técnico, com a elaboração do "Referencial curricular para Curso Técnico de Agentes Comunitário de Saúde”16. A Lei no 10.507 teve o papel de reconhecer os ACS como uma categoria profissional e de incentivar o processo de formação desses trabalhadores.

Contudo, na maioria das regiões do país, os ACS iniciaram seus trabalhos sem formação específica, receberam apenas informações básicas sobre o que coletar em suas visitas e aprenderam no cotidiano do seu trabalho o aprender-fazendo, dependendo do critério e iniciativa pessoal ${ }^{17}$.

Os autores enfatizam que a qualificação é importante, já que esse profissional não tem contato com ferramentas de ensino-aprendizagem que possam aliar o conhecimento popular trazido da comunidade com o conhecimento técnico-científico, indispensável para a apropriação de práticas de promoção à saúde.

Os dados da presente pesquisa mostram descontinuidade na oferta do curso de Formação Inicial do ACS para assistência à comunidade por parte da Secretaria Municipal de Saúde (SESMA). Alguns relatos de ACS, que ingressaram no programa no período de 2006 e 2007, evidenciam essa lacuna e as estratégias que utilizaram para tentar contorná-la:

[...] Não tive o curso de formação, mas, com o decorrer do trabalho, fui adquirindo com os amigos de profissão, os mais antigos [...] ACS-40

[...] Não fiz nenhum curso; baseei-me nas experiências adquiridas nos serviços prestados como voluntário na pastoral da criança e no serviço comunitário [...] ACS-01

Diante do novo perfil de atuação para o ACS, precisam ser adotadas formas mais abrangentes e organizadas de formação com propostas educativas críticas capazes de referenciar-se na realidade das práticas e nas transformações políticas, tecnológicas e científicas relacionadas à saúde e de assegurar o domínio de conhecimento e habilidades específicas para o desempenho de suas funções ${ }^{18}$.

Além da descontinuidade na oferta do curso de Formação Inicial, também se observou falta de padronização na carga horária nos cursos oferecidos pela SESMA (Tabela 2). As respostas dos ACS permitiram identificar uma variação importante, o que sugere a inexistência de uma proposta educativa estruturada e contínua.

O primeiro projeto de qualificação do ACS foi promovido pela Secretaria de Gestão do Trabalho e Educação na Saúde (SGETES) no governo de Lula e constituiu uma proposta de qualificação profissional de nível básico, de 80 horas. Após, considerou-se necessária uma melhor qualificação desse profissional frente à 
complexidade das ações por ele desenvolvidas, o que levaria a aumento da carga horária. A formação foi assumida pelas escolas técnicas do SUS, que passaram a discutir um perfil de competências e a formação dos ACS. Porém, o município de Altamira, pese a sua importância na região, não participou desse processo, ficando a critério dos gestores o processo de formação.

$\mathrm{Na}$ presente pesquisa os ACS foram indagados se o curso de Formação Inicial os preparou para a desenvolver as atribuições previstas na legislação e se foram abordados assuntos sobre as ações educativas que precisam desenvolver na comunidade (Tabela 2). Sobre o primeiro aspecto, 52 ACS relataram que o curso os formou adequadamente, oito disseram que não e três, que parcialmente. Porém, enfatizam déficit no relacionado a participação em programas sociais, além da ESF, o que é preocupante considerando a realidade da região. No preparo para desenvolver ações educativas junto à comunidade, 53 se mostraram satisfeitos, oito, não e dois, parcialmente.

Indagados sobre quais os aspectos que precisariam ser aprofundados durante a Formação Inicial e permanente, os ACS demandaram mais conhecimentos específicos sobre álcool e drogas e vigilância em saúde, procedimentos técnicos de saúde, comunicação, relacionamento interpessoal, ética e identidade profissional.

A satisfação com o processo educativo durante o curso de Formação Inicial também foi observado nas questões abertas do questionário. Nelas, emergiram várias falas que possibilitaram a organização em duas unidades temáticas:

1. Inserção na Comunidade e

2. Subsídios para desenvolver Práticas Educativas.

A primeira unidade, Inserção na Comunidade, emergiu das seguintes falas:

[...] Preparou-me para que tivesse um elo de ligação com a comunidade, pois ela é a principal interessada e ela [a formação inicial] é muito importante para desenvolver esses trabalhos educativos [...] ACS-27

[...] uma ajuda na hora de conversar com a comunidade, como informar as pessoas o modo de trabalho, cada dia um aprendizado [...] ACS-22

[...] O curso faz com que os ACS conheçam a realidade, que as ações educativas devem ser feitas na comunidade conforme as necessidades exigidas, e é um curso muito importante [...] ACS-31

Nota-se, que os ACS valorizam no curso de Formação Inicial, as aprendizagens sobre comunicação e o papel de agente articulador entre a comunidade e os serviços de saúde. Assim, a percepção desses agentes em relação ao contexto de cada comunidade é ponto fundamental para o processo educativo e participativo da população ${ }^{5,14}$.
A segunda unidade temática, Subsídios para desenvolver Práticas Educativas, foi apreendida das seguintes falas:

[...] me preparou para realizar nas atividades como a orientação e informação básica para desenvolver o trabalho como palestra no colégio, posto de saúde e outros. ACS-16

[...] em educação em saúde visando à prevenção, através de palestras, visitas domiciliares. ACS-57

As ações educativas abordadas durante o curso de Formação Inicial denotam um predomínio de modelo tradicional de práticas centradas no profissional, como são as palestras, o que pode dificultar a interação e a compreensão da realidade dos sujeitos da comunidade levando em conta suas reais necessidades e saberes.

A educação popular vem a se contrapor a este modelo, já que é compreendida como um conjunto de pressupostos políticos, filosóficos e pedagógicos, cujos alicerces principais são a valorização da cultura; o diálogo, a ética e a democracia, no processo de construção de relações sociais mais justas. Nesta perspectiva, existe a necessidade de ter, como referência constante as condições de vida das pessoas e a forma como elas convivem com essa realidade; a relação entre conhecimento e politização, entre educação e movimentos sociais, além da atenção ao cotidiano da sociedade ${ }^{19}$.

No processo de formação do ACS, é relevante procurar a integração entre o conhecimento científico-técnico da área saúde e os conhecimentos construídos pela população, narrados e acumulados em suas experiências de lidar com as situações de adoecimento e de assistência precária dos serviços públicos. Nessa linha, a educação popular implica abrir caminho para que a ciência se aproxime do cotidiano das pessoas ${ }^{20}$.

O processo de construção da identidade profissional do ACS, detentor de saberes populares e, por sua vez, interessado em se apropriar dos conhecimentos e vocabulário científicos próprios da área, apresenta complexidade, já que o domínio destes não pode ser um fator que o distancie da comunidade atendida.

Nem sempre é conveniente à substituição de saberes do senso comum por conhecimentos científicos, uma vez que existem saberes do cotidiano consagrado em determinadas culturas que podem ser válidos de acordo ao contexto de demandas sociais das tarefas ${ }^{21}$. $\mathrm{O}$ autor, baseado numa perspectiva sociocultural defende que

Uma pessoa poderia adquirir a capacidade de distinguir essa maneira cotidiana de ver o mundo de maneiras mais sofisticadas. Substituir essas concepções 'alternativas', no entanto, significaria suprimir o pensamento do senso comum e seu modo de expressão, a linguagem cotidiana. Uma experiência irreal e inútil. A linguagem cotidiana é o modo mais abrangente de se compartilhar significados.

O legítimo e necessário desejo de aprimoramento profissional e construção de identidade do ACS requer a conscientização sobre 
estes diferentes saberes para levar a tomada de decisões que aprimorem o seu papel educativo estratégico junto à comunidade e seu papel de nexo entre ela e os profissionais dos serviços.

Isto adquire maior relevância uma vez que a maioria dos profissionais da área da saúde é formada ainda num modelo biomédico com visão fragmentada e distante do preconizado nas Diretrizes Curriculares Nacionais ${ }^{22}$, que enfatizam a atenção básica á saúde e o desenvolvimento de competências como a comunicação e a liderança e tomada de decisões para conduzir processos de transformação e democratização social, dentre outras ${ }^{23}$.

As características mais citadas pelos ACS nesta pesquisa reforçam o entendimento de seu papel mediador, educativo e comunicativo. Dada a relevância da comunicação dialógica, valoriza-se o espaço das relações interpessoais estabelecidas nos serviços de saúde como contexto de práticas educacionais. Todo profissional de saúde é um educador em saúde em potencial, sendo condição essencial à sua prática seu próprio reconhecimento enquanto sujeito do processo educativo, bem como o reconhecimento dos usuários enquanto atores em busca de autonomia ${ }^{24,25}$.

As seguintes expressões reforçam o leque das qualidades valorizadas pelos ACS para exercer as suas funções e o comprometimento com a comunidade:

[...] ser compreensivo, tentar ajudar a comunidade, sempre a comunidade é alvo de tudo; sempre ela tem que estar em primeiro lugar. ACS-21

[...] os ACS deveriam ser mais valorizados porque nós somos informantes de tudo que acontece na nossa comunidade. ACS-38

O ACS é o trabalhador com muitas funções estratégicas, o que requer uma complexa gama de atributos, para viabilização das metas da atenção preconizadas estabelecendo aproximações e construindo vínculos com a comunidade atendida. O ACS constitui o elemento nuclear da realização de determinadas políticas de saúde, em especial de programas que expressam modelos para reorientação da assistência à saúde no país ${ }^{26}$.

Os ACS são conscientes de seu relevante papel na atenção primária à saúde, o que potencializa as suas ações (APS). Neste cenário, torna-se primordial conhecer seu perfil socioeconômico, processo e demandas de formação, o cumprimento das suas atribuições legais e o entendimento do seu papel educativo junto à comunidade. Esse conhecimento possibilita estabelecer estratégias que favoreçam o delineamento de políticas que contribuam para a consolidação do atual sistema de saúde, especialmente nas regiões dos países com maiores demandas.

Observou-se que esses profissionais, no que diz respeito ao seu perfil, atendem aos pré-requisitos/critérios exigidos pela ESF por meio da Política Nacional da Atenção Básica, segundo portaria $\mathrm{n}^{\circ} 2.488$, de 21 de outubro de 2011, notadamente no que concerne à escolaridade, ao fato de residir no município e fazer parte representativa da comunidade atendida.

A tendência de aumento na escolaridade favorece a construção de sua identidade profissional e o preparo para a sua atuação profissional. Existe o entendimento, por parte dos ACS entrevistados, da importância da sua função social e o papel de mediação, elo e comunicação junto à população, o que demanda um leque de características necessárias para o exercício de suas funções que abrangem aspectos conceituais, pedagógicos, éticos e sócio-políticos. Os participantes apontam ainda a necessidade de ampliação de seu processo formativo que levem ao maior reconhecimento e valorização do seu papel por parte dos gestores, equipe de saúde e sociedade.

O curso de Formação Inicial mostrou descontinuidade e carência de uma adequada estruturação no oferecimento o que evidencia a necessidade de padronização, não apenas com relação à carga horária, mas também na ampliação de referenciais teóricos sobre o modelo pedagógico adotado. Este precisa ser condizente com o seu papel de interlocutor entre a equipe de saúde e a comunidade o que envolve competências dialógico-educativas e a valorização dos saberes populares. A complexidade das demandas exige qualificação dos agentes de forma a potencializar seu vínculo com a comunidade e com os profissionais da equipe de saúde, ainda formados, na sua maioria, numa perspectiva científico-tecnicista.

As atribuições previstas na legislação são amplamente atendidas por parte dos ACS. Porém, considerando os atuais desafios decorrentes da construção da usina de Belo Monte, são necessárias ações no sentido de favorecer a sua atuação nos programas sociais implantados pelos governos federal, estadual e municipal na região, que sofre fortes impactos sociais e ambientais.

As transformações por eles pretendidas englobam diversos fatores e diferentes participantes, os quais necessitam ser conhecidos e compreendidos de forma que, por meio de ações conjuntas, seja possível traçar o caminho para alcançar a meta maior, qual seja, a formação de um profissional que ocupa lugar estratégico para atender às demandas da comunidade assistida.

\section{REFERÊNCIAS}

1. Tomaz JBC. O agente comunitário de saúde não deve ser um "super-herói". Interface (Botucatu). 2002;6(10):84-7. http://dx.doi.org/10.1590/S1414-32832002000100008
2. Brasil. Ministério da Saúde. Secretaria de Políticas de Saúde. O trabalho do agente comunitário de saúde. Brasília: Ministério da Saúde; 2000. 
3. Silva JA, Dalmaso ASW. O agente comunitário de saúde e suas atribuições: os desafios para os processos de formação de recursos humanos em saúde. Interface (Botucatu). 2002;6(10):75-83. http://dx.doi.org/10.1590/S1414-32832002000100007

4. Brasil. Ministério da Saúde. Secretaria de Políticas de Saúde. Projeto Promoção da Saúde. As cartas da promoção da saúde. Brasília: Ministério da Saúde; 2002.

5. Fundação Oswaldo Cruz. Escola Politécnica de Saúde Joaquim Venâncio. Laboratório de Trabalho e Educação Profissional em Saúde. Projeto memória da educação profissional em saúde. Rio de Janeiro: Observatório dos Técnicos em Saúde; 2006.

6. Gil AC. Como elaborar projetos de pesquisa. $4^{a}$ ed. São Paulo: Atlas; 2002.

7. Lakatos EM, Marconi MA. Fundamentos da metodologia científica. $7^{a}$ ed. São Paulo: Atlas; 2010.

8. Minayo MCS. O desafio do conhecimento: pesquisa qualitativa em saúde. 12ª ed. São Paulo: Hucitec; 2010.

9. Instituto Brasileiro de Geografia e Estatística. Pesquisa Nacional por Amostra de Domicílios: síntese de indicadores. v. 31. IBGE; 2011.

10. Dias S, Gonçalves A. Migração e Saúde. Rev Migrações. 2007;(1):15-26.

11. Santana JCB, Vasconcelos AL, Martins CV, Barros JV, Soares JM, Dutra BS. Agente comunitário de saúde: percepções na estratégia saúde da família. Cogitare Enferm. 2009;14(4):645-52.

12. Mota RRA, David HMSL. A crescente escolarização do agente comunitário de saúde: uma introdução do processo de trabalho? Trab Educ Saúde. 2010;8(2):229-48. http://dx.doi.org/10.1590/S1981-77462010000200004

13. Brasil. Lei $n^{\circ} 11350$, de 05 de Outubro de 2006. Regulamenta o $\S 50$ do art. 198 da Constituição, dispõe sobre o aproveitamento de pessoal amparado pelo parágrafo único do art. 20 da Emenda Constitucional no 51, de 14 de fevereiro de 2006, e dá outras providências. Disponível em: http://www. planalto.gov.br/ccivil_03/_ ato2004-2006/2006/lei//11350.htm. Acesso em: 17 jun. 2013.

14. Nunes MO, Trad LB, Almeida BA, Homem CR, Melo MCIC. O agente comunitário de saúde: construção da identidade desse personagem híbrido e polifônico. Cad Saúde Pública. 2002;18(6):1639-46. http://dx.doi.org/10.1590/S0102-311X2002000600018
15. Ferraz L, Aerts DRLC. O cotidiano de trabalho do agente comunitário de saúde no PSF em Porto Alegre. Ciênc Saúde Coletiva. 2005:10(2):347-55 http://dx.doi.org/10.1590/S1413-81232005000200012

16. Brasil. Ministério da Educação. Referencial curricular para o curso técnico de agente comunitário de saúde: área profissional saúde. Brasília: Ministério da Saúde; 2004.

17. Coriolano MWL, Lima MM, Queiroga BAM, Ruiz-Moreno L, Lima LS. Educação Permanente com Agentes Comunitários de Saúde: Uma Proposta de cuidado com crianças asmáticas. Trab Educ Saúde. 2012;10(1):37-59 http://dx.doi.org/10.1590/S1981-77462012000100003

18. Brasil. Presidência da República. Decreto Federal n 3.189/99. Fixa diretrizes para o exercício da atividade de Agente Comunitário de Saúde (ACS), e dá outras providências. Disponível em: http:// www.planalto.gov.br/ccivil_03/decreto/D3189.htm. Acesso em: 17 jun. 2013.

19. Freire P. Educação e mudança. $8^{a}$ ed. Rio de Janeiro: Paz e Terra; 1983; p. 79

20. Vasconcelos EM. Educação popular e a atenção á saúde da família. São Paulo: Hucitec; 2006.

21. Mortimer EF. Linguagem e formação de conceitos no ensino de ciências. $2^{\mathrm{a}}$ ed. Belo Horizonte: Editora UFMG: 2011.

22. Brasil. Ministério da Educação. Conselho Nacional de Educação. Parecer CNE/CES 1.133/2001, de 7 de agosto de 2001. Diretrizes curriculares nacionais dos cursos de graduação em enfermagem, medicina e nutrição. Brasília: 2001.

23. Ruiz-Moreno L, Sonzogno MC. Formação Pedagógica na Pós-Graduação em Saúde no Ambiente Moodle: um compromisso social. Pró-Posições. 2011;22(3):149-64.

24. L'Abbate S. Educação em saúde: uma nova abordagem. Cad Saúde Pública. 1994;10(4):481-90. http://dx.doi.org/10.1590/S0102-311X1994000400008

25. Smeke ELM, Oliveira, NLS. Educação em Saúde e concepções de sujeito. São Paulo: Hucitec; 2001; p. 115-36.

26. Silva JA, Dalmaso ASW. Agente comunitário de saúde: o ser, o fazer. Rio de Janeiro: Fiocruz; 2002; 240 p. 